\title{
Daytime Sleepiness and Changes of Sleep in Patients with Epilepsy
}

\author{
Katarína Klobučníková and Branislav Kollár \\ I st Department of Neurology University Hospital of Medical Faculty, \\ Comenius University,Bratislava, \\ Slovak Republic
}

\section{Introduction}

It is well known, that patients with epilepsy suffer from excessive daytime sleepiness, fatigue and insufficient sleep. These problems are often overlooked or referred to epileptic seizures or antiepileptic drugs. It should be noticed, that patients with epilepsy suffer from sleep disorders more often than general population (Bazil 2003). Health outcome of patients with comorbidity of epilepsy and sleep disorders is worse as sleep disorders may aggravate epilepsy. Changes in amount and severity of epileptic seizures may lead to pharmacoresistency of epilepsy in patients with untreated sleep disorders. That is the reason why attention to quality of sleep and daytime vigility in patients with epilepsy should be payed. The cooperation of neurologist, pneumologist, somnologist and psychologist is very important in correct management of patients with epilepsy and sleep disorders.

Daytime sleepiness is defined as the inability to stay awake during waking episodes of the day. It results in unintended lapses into drowsiness or sleep. Sleepiness occurs mainly in boring situations. Sometimes it is associated with increase of total amnount of sleep without feeling of restoration. In most cases excessive daytime sleepiness (EDS) is a chronic symptom and it must occur for at least three months prior to diagnosis (ICSD-2, 2005).

Excessive daytime sleepiness is often result of self-imposed sleep deprivation espetially in young people. More often it is effect of disturbed nocturnal sleep or misaligned circadian rhytms. It may be side effect of many often-used drugs, for example hypnotics or alcohol. Nocturnal sleep disturbances, which lead to EDS, should be carefully assessed and treated. In several conditions EDS is not an outcome of night-sleep loss and should be considered as primary hypersomnia of central origin. These hypersomnias according to ICSD-2 include narcolepsy with or without cataplexy, recurrent hypersomnia, idiopathic hypersomnia with or without long sleep time and hypersomnias due to different medical and neurological conditions. Narcolepsy with cataplexy is characretized with daytime sleepiness and unwanted episodes of sleep, which occur several times a day. The duration of episodes may vary from a few minutes to more than an hour, patients wake up refreshed. Cataplexy is paroxyzmal, abrupt and reversible loss of muscule tone often elicited with emotional experience. Manifestations of disociated REM sleep (sleep paralysis and hypnagogic halucinations) are also exposed (Chokverty, 1994). Narcolepsy without cataplexy is associated with snoozing in daytime, sleep paralysis and hypnagogic hallucinations may occur. Secondary narcolepsy may be caused by tumors of brain or multiple sclerosis, if 
hypothalamus is harmed. Recurrent hypersomnia, Kleine-Levin syndrome, is characterized by atacs of hypersomnia, which lasts for several days and occur several times per year. Episodes are accompanied by disturbances of behaviour (agression), bulimia and hypersexiality. Idiopathic hypersomnia with long sleep time is characterized by constant and sever EDS with unrefreshing naps of up to four hours and prolonged major sleep episode up to $10-14$ hours. There are great difficulties with morning waking up and sleep drunkeness. Idiopathic hypersomnia without long sleep time, or essential hypersomnia is characterized with constant and sever EDS, which results in unintended naps of nonrefreshing nature. Cataplexa is absent. The major sleep episode is either normal, or slightly prolonged (to 10 hours). Post-wakening confusion of often reported.

Behaviorally induced insufficient sleep syndrome is another reason of EDS. A therapeutic trial of a longer sleep episode can reverse the symptoms. Hypersomnia has been described also in association with a large range of medical conditions, including head trauma, stroke, encephalitis, inflammatory conditions, tumors and neurodegenerative diseases as M.Parkinson (ICSD-2), (Overeem \& Readings , 2010).

\subsection{Diagnostic evaluation of sleepiness in patient with epilepsy}

Obtaining an accurate 24-hour-sleep-wake history is extremly important. History should be focused also on relevant factors as medical history, compensation of epilepsy, type and frequency of epileptic seizures, their incidence according to circadian cycle and actual antiepileptic medication, or other drug and medication use. Also social, enviromental or psychological conditions, which may interfere with sleep quality, should be evaluated.

Neurological examination in connection with neuroimaging methods (MRI) can detect cerebral leasions as the reason of sleep problems. Standard EEG evaluation is recommended to detect abnormalities in EEG activity and interictal epileptic discharges. Epworth Scale of Sleepiness (ESS) is widely used questionnaire to quantify severity of daytine sleepiness. Score above 9 indicates elevated daytime sleepiness (Johns, 1991).

Multiple Sleep Latency Test (MSLT) can objectively evaluate daytime sleepiness. When used as diagnostic prosedure of central hypersomnia it should be done during the day after polysomnographically documented adequate night sleep, which lasts at least six hours and after two weeks of regular sleep. (Carscadon \& Dement, 1982, American sleep disorders association, 1992) (ICSD-2, 2005). Evaluation of MSLT starts 1,5-3 hours after morning awakening and consists of 5 , or at least 4 records of polysomnography, each lasting 20minutes (Littner et al., 2005). Latency of sleep and occurence and latency of REM sleep is in each record noted. A mean sleep latency below five minutes is generally considered as indicative of sleepiness, latency over ten minutes is generally considered indicative of normal alertness (American Sleep Disorders Association, 1992).

\subsection{Correlation of sleep and epilepsy}

Relationship of sleep and epilepsy is complex and reciprocal. Epilepsy may distrub sleep with night and also daytime epileptic seizures. On the other hand sleep modulates probabality of epileptic discharges and seizures in different sleep stages.

Specific types of epilepsy are bounded to specific part of sleep-wake cycle, as night sleep, awakening, or appear randomly during circadian rhytm. Typical night epilepsy is for example nocturnal frontal lobe epilepsy (Zucconi, 2007), juvenile myoclonical epilepsy is typically connected to awakening. Sleep deprivation elevates probabality of epileptic seizure (Bazil, 
Malow \& Sammaritano, 2002), what is widely used in EEG evaluation. Influence of antiepileptic medication on daytime vigility and quality of sleep is also important. Unrecognised primary sleep disorders, which cause fragmentation of sleep, may aggravate epilepsy and increase amount of epileptic seizures. Distinction of sleep-related epileptic seizures and non-epileptic paroxymal events in sleep is frequently problematic and requires careful diagnostic approach with video-polysomnography (Moráň, 2005).

Unrecognised sleep-related generalised epileptic seizures disturb sleep achritecture as they cause arousals. Generalized epileptic seizures reduce total sleep time and elongate latency to REM sleep. Amount of NREM1 and NREM2 stages may be extended (Foldvary-Schaefer, 2002). Partial epileptic seizures during sleep do not disrupt night sleep markedly, only in case of their secondary generalization (Dasheiff, 2003). Epileptic seizures during daytime influence night sleep too. They reduce REM sleep, what may be cause of fatigue in postparoxysmal period (Bazil, Castro \& Walczak, 2000).

Antiepileptic therapy is considered to have influence on daytime vigility and quality of sleep. Barbiturates and benzodiazepines have sedative effect and cause daytime sleepiness (Bazil, 2003, Rang \& Dale, 1991). Carbamazepine also induces daytime sleepiness, elongates slow-wave sleep and reduces REM sleep, mainly in the beginning of medication. Approximately after one month of medication these effects are not more noticeable (Placidi et al., 2000). Valproate according to literature elongates NREM1 and abbreviates NREM2 (Foldvary-Schaefer, 2009). It elevates number of arousals and elongates slow-wave sleep (Morán̆, 2005). Put on weight may be unfavorable for patients with sleep apnoe syndrome (Moráň, 2003).

Primidone abbreviates latency of sleep and may improve quality of sleep. Phenytoin extends NREM1 and NREM2, shorten REM period and multiplies arousals. Gabapentin improves sleep stability and elongates slow-wave sleep as well as REM sleep (Foldvary-Schaefer, 2009). Lamotrigine reduces NREM3 and NREM4 and elongates REM sleep (Foldvary, 2002). As alerting drug should be dosed early in the day. Sleep latency may be shortened by topiramate (Foldvary-Schaefer, 2009). Levetiracetam consolidates sleep and does not modify vigilance (Cicolin, 2006). According to othe study (Cho, Kim \& Motamendi, 2011) levetiracetam increase sleep efficiency without major effects on sleep structure. Antiepileptic drugs may be helpful in treatment of some sleep disorders. For example gabapentin, carbamazepine or lamotrigine have good effect on restles leg syndrome (Garcia-Borreguero et al, 2002).

\subsection{Sleep disorders and epilepsy}

Exact evidence about incidence of sleep disorders in patients with epilepsy is not available, but it is supposed, that the amount is higher in patients with epilepsy than in general population. For example patients with partial epilepsy have twice higher appearence of sleep disorders as in healthy group (39\% vs 18\%) (Bazil, 2003). According to this study higher presence of sleep disorders did not correlate with antiepileptic therapy.

According to Foldvary-Schaefer (2002) patients with epilepsy have problems with initialization of sleep and have worse quality of sleep. Meatiness of these problems, as well as wores control of epileptic seizures, was higher in group of patients with partial epilepsy. Some literature indicates, that patients with epilepsy have also higher appearance of sleep related breathing disorders than general population. Sleep apnoe syndromes are present in $0,8-2,2 \%$ of general adult population (Marin et at., 1997), however $28-55 \%$ patients with epilepsy suffer for sleep related disorders (Foldvary, 2002). 
Even 33\% pacients with medically refractory epilepsy have sleep apnoe syndrome (Malow et al., 2000). Reason of higher appearance of sleep related breathing disorders in patients with epilepsy is not clear. It may be connected with higher weight of patients as effect of anticonvulsant therapy (Manni \& Terzaghi, 2010), or changes of endocrine system (valproate). Sleep apnoe syndrome leads to fragmented macroarchitecture of sleep with repeated hypoxemia of brain in consequence of repeated apnoic episodes. This may cause higher frequency of epileptic seizures. It is important, that correct therapy of sleep apnoe syndrome (reduction of weight, indication of CPAP or BiPAP) may bring improvement of epilepsy (Foldvary, 2002).

Sleep disorders should be considered especially when patient with epilepsy indicates hypersomnia, but has low frequency of epileptic seizures, is treated with monotherapy of antiepileptic drug and has low blood levels of medication.

\subsection{Management of patient with epilepsy and sleep disorders}

Patient with epilepsy and EDS reguires accurate evaluation to detect reason of hypersomnia. Compensation of epilepsy should be examined. EEG during daytime and overnight-EEG should detect interictal or ictal discharges. This may cause microarousals and fragmentation of sleep with secondary hypersomnia. Adjusting of antiepileptic medication should reduce amount of epileptic seizures and improve sleep. It is recommended to avoid antiepileptic therapy with sedative effects (barbiturates, benzodiazepines) and useless combination of too many antiepileptic drugs.

Correct sleep hygiene and life-style with regular and sufficient night-sleep and optimal surroundings is also important (Bazil, 2003, Happe, 2003).

Hypersomnia in patients with epilepsy may be caused by sleep apnoe syndrome. This should be considered particulary in obese patients with morning headache and hypertension. Diagnosis is estimated by polysomnography. According to literature $1 / 3$ patients with refractory epilepsy have obstructive sleep apnoe syndrome (Malow et al., 2000). Correct therapy of sleep related breathing disorders may improve quality of sleep. Antiepileptic therapy, which increase weight (valproate) should be avoided, as it may worsten sleep apnoe syndrome (Bazil et al., 2002).

Insomnia is another possible reason of daytime hypersomnia and fatigue of patients with epilepsy. It should be treated by behavioral and relaxation methods, improvement of sleep habits or by sedative drugs. If antiepileptic therapy is considered as reason of insomnia, then it should be taken only in morning.

\section{Objectives}

Targets of this study were:

- to determine daytime sleepiness in patients with epilepsy by Epworth scale of sleepiness and Multiple Sleep Latency Test and compare it with healthy controls

- to investigate sleep architecture of patients with epilepsy and compare changes with healthy controls

- to find out, if detected changes of sleep architecture correlate with some characteristics of epilepsy

\section{Methodology}

All patients underwent standard EEG evaluation with 21 canal EEG machine and distribution of electrodes according to system 10-20, duration of record was 20 minutes. 
Noticed abnormalities were rated as regional or generalised, with continual of intermitent occurence. Appearance of epileptiform ictal or interictal discharges was noted.

\subsection{Methods used to examine daytime sleepiness}

In both groups (patients with epilepsy and healthy controls) we used a questionnaire Epworth Scale of Sleepiness (ESS) (Johns, 1991). By answering eight questions about probability of falling asleep in standard situations we came to the result, i.e. score of daytime sleepiness ranging from 0 to 24 . Rate $0-9$ is considered as normal value, above 9 as elevated daytime sleepiness and value above 16 is considered as remarkably elevated daytime sleepiness (Watanabe et al., 2003).

All patients with epilepsy were evaluated by Multiple Sleep Latency Test (MSLT) (Carscadon \& Dement, 1982) in order to objectivise the daytime sleepiness. The latency of sleep was measured in five 20 minute polysomnographic registrations in this test. Between the registrations the patient should be awake (Usui et al., 2008). Mean latency of sleep and appearance of REM sleep was noticed. Mean latency of sleep shorter than 6 minutes was considered as indicative of elevated sleepiness (American sleep disorders association, 1992).

\subsection{Methods used to register sleep architecture}

Nocturnal polysomnografy was used in both groups to evaluate quality of sleep. We used program Brain Quick System 98 for polysomnography. Scoring of sleep stages was done with Sleep View Rembrandt Sleep Analysis Program.

Registration and scoring of sleep stages was done according to criteria of Manual of Standardized Terminology, Techniques and Scoring System for Sleep Stages of Human Subjects (Rechtschaffen \& Kales, 1968). We used four electrodes (C3, C4, O1, O2, A1, A2) in EEG registration. When topographical localization of epileptiform discharges was needed, we used 19 EEG electrodes located according to international system 10-20. Standard localization of electrodes for electrooculogram and electromyogram m.mentalis was used.

The result of sleep analysis was hypnogram, amount of sleep stages (NREM S1, NREM S2, NREM S3+-S4, REM) in \%, total sleep time in minutes and efficiency of sleep in \%was marked. For purpose of registration of different abnormal movement manifestations (epilepsy, REM behavior diseases etc.), a video was recorded simultaneously with polysomnography.

\subsection{Characteristics of the group of patients with epilepsy}

We examined 100 patients with epilepsy who were admitted to the I. Neurology Clinic of Comenius University Hospital in Bratislava for diagnostic or therapeutic reasons in the period from January 2004 to January 2009. The group consisted of 49 men and 51 women, with the average age of $34.68 \pm 13.55$ years. Patients of the age 9 - 61 were included. Average duration of illness was $9.31 \pm 9.93$ years, ranging from 0.5 to 47 years. Medical history of duration and type of epilepsy was taken. International classification of epileptic seizures (1981, 1989) and International classification of epilepsy (1989) was used.

According to this classification 50 patients had focal symptomatic epilepsy, 26 patients had focal cryptogenic epilepsy. Generalised symptomatic epilepsy was diagnosed by 15 pacients and 9 patients had generalised cryptogenic or idiopathic epilepsy (see Fig.1).

Etiology of epilepsy was evaluated. Idiopathic or cryptogenic epilepsy have $35 \%$ patients and symptomatic epilepsy have $65 \%$ of patients. Detailed analysis of reasons of epilepsy in group of symptomatic patients showed these factors: 
- $\quad$ vascular (stoke) had 13 patients $(20 \%)$

- perinatal lesion of brain had 13 patients $(20 \%)$

- $\quad$ prenatal damage of brain had 10 patients $(15,4 \%)$

- $\quad$ injury and posttraumatic lesion had 6 patients $(9,2 \%)$

- $\quad$ tumors of brain had 8 patients $(12,3 \%)$

- multiple sclerosis and other demyelinization diseases of brain - 5 patients $(7,7 \%)$

- $\quad$ residual damage of brain after inflammatory disease - 5 patients $(7,7 \%)$

- $\quad$ arteriovenous malformation -3 patients $(4,6 \%)$

- $\quad$ exotoxic encefalopathy -2 patients $(3 \%)$

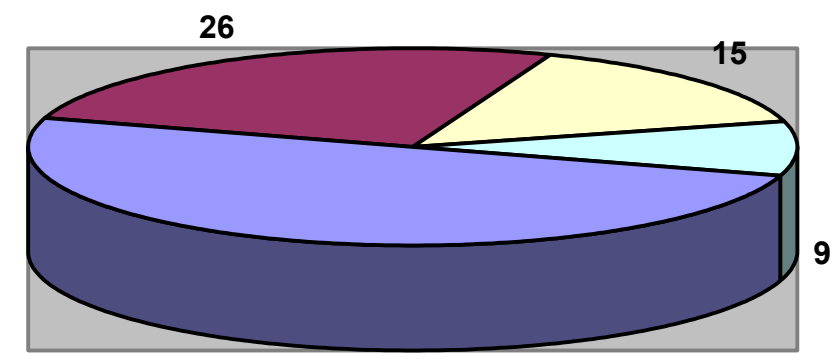

50

\begin{tabular}{|ll|}
\hline$\square$ Foc. symp. epi & GFoc. crypt. + idiop. epi \\
$\square$ Gen. sympt. epi & $\square$ Gen.crypt.+idiopat. epi \\
\hline
\end{tabular}

Fig. 1. Amount of patients according to type of epilepsy

Compensation of epilepsy was evaluated according to Diagnostic and therapeutic standard of epilepsy (Donáth, 1996). As insufficiently compensated epilepsy were rated patients with several epileptic seizures during last month. Partially compensated epilepsy had patients with minimally half of year seizure free period and fully compensated epilepsy had patients, who had not for last 3 years an epileptic seizure. According to these criteria 80 patients had insufficiently compensated epilepsy and 20 patients were rated as having partially or fully compensated epilepsy.

All patients were treated by antiepileptic medication. Monotherapy used 59 patients $(59 \%)$, 29 pacients (29\%) were treated by two antiepileptic drugs (AEDs) and 12 pacients (12\%) have three and more AEDs (see Fig.2).

Most frequently used monotherapy was carbamazepine, which used 31 patients (it was $52,5 \%$ of patients treated by monotherapy). Valproate as monotherapy used 14 pacients (23,7\% of patients on monotherapy), 10 patient $(16,9 \%)$ used lamotrigin, one pacient $(1,7 \%)$ used primidon, one patient $(1,7 \%)$ was treated by clonazepam, one patient $(1,7 \%)$ gabapentin and one patient phenytoin (1,7\%) (see Fig.3).

Two AEDs were used by 29 patients. Most frequent combination of EADs was carbamazepine /valproate, which used 9 patients $(31 \%$ of all patients on combination of two AEDs). Next most commonly used combination of two AEDs was valproate/ lamotrigine used by 6 patients $(20,7 \%$ of all patients on combination of two AEDs). Three 
patients used combination of lamotrigine/topiramate. Two patients used combination of carbamazepine/lamotrigine, carbamazepine/topiramate and combination valproate/ topiramate. One patient used combination carbamazepine/levetiracetam, carbamazepine/ gabapentin, carbamazepine/pregabalin, valproate/levetiracetam and topiramate/ zonisamid (see Table 1).

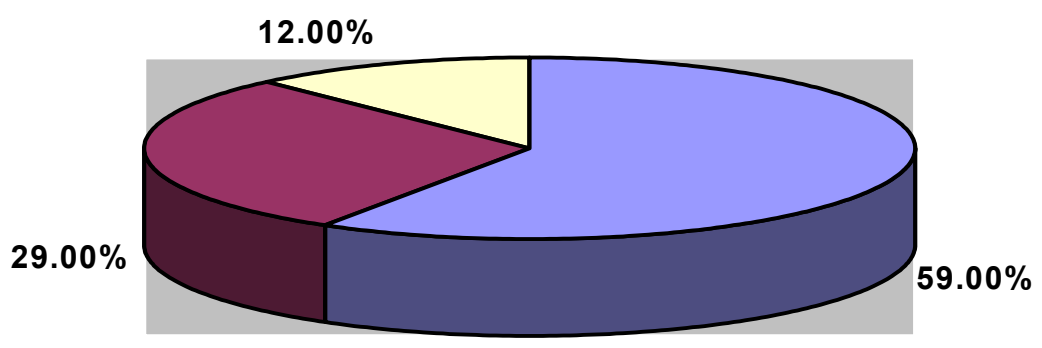

$\square$ Monotherapy AED $\square$ Two AEDs $\square$ Three and more AEDs

Fig. 2. Antiepileptic therapy in group of epileptic patients.

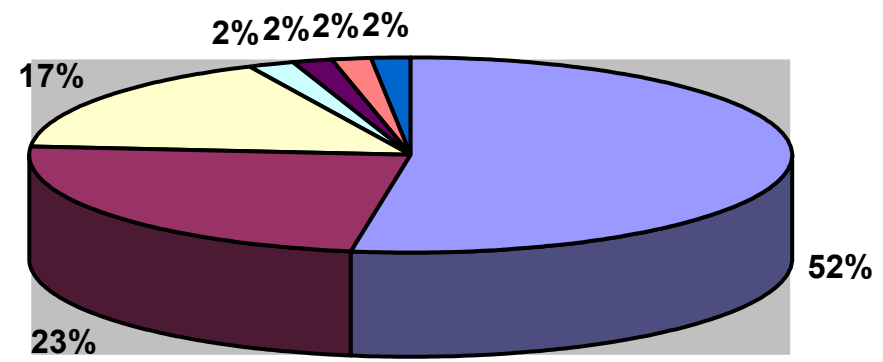

\begin{tabular}{|c|c|c|}
\hline$\square$ Carbamazepine & $\square$ Valproate & $\square$ Lamotrigine \\
\hline$\square$ Primidon & $\square$ Clonazepam & $\square$ Gabapentin \\
\hline
\end{tabular}

Fig. 3. Antiepileptic monotherapy in group of epileptic seuzures. 


\begin{tabular}{|c|c|c|c|c|c|c|c|c|c|c|c|c|c|c|c|c|c|c|c|c|c|c|c|c|c|c|c|c|c|}
\hline Carb. & + & + & + & + & + & + & + & + & + & + & + & + & + & + & + & + & & & & & & & & & & & & \\
\hline Valpr. & + & + & + & + & + & + & + & + & + & & & & & & & & + & + & + & + & + & + & + & + & + & & & \\
\hline Lamic. & & & & & & & & & + & + & & & & & & + & + & + & + & + & + & & & + & + & + & \\
\hline Topir. & & & & & & & & & & & + & + & & & & & & & & & & + & + & & + & + & + & + \\
\hline Levet. & & & & & & & & & & & & & + & & & & & & & & & & & + & & & \\
\hline Zonis. & & & & & & & & & & & & & & & & & & & & & & & & & & & & + \\
\hline Gabap & & & & & & & & & & & & & & + & & & & & & & & & & & & & \\
\hline Pregab & & & & & & & & & & & & & & & + & & & & & & & & & & & \\
\hline
\end{tabular}

Table 1. Combinations of two AEDs used in the group of patients with epilepsy.

Combination of three and more AEDs was used by 11 patients. Most commonly used combination of AEDs was carbamazepine/ valproate/lamotrigine, which used 7 pacientov, next combinations see in table 2.

\begin{tabular}{|l|l|l|l|l|l|l|l|l|l|l|l|l|l|l|l|l|}
\hline Carbam. & + & + & + & + & + & + & + & + & + & + & + & + \\
\hline Valproate & + & + & + & + & + & + & + & + & + & + & + & \\
\hline Lamotrig. & + & + & + & + & + & + & + & & & & & & & + \\
\hline Topiramate & & & & & & & & & & & + & & + \\
\hline Levetirac. & & & & & & & & & & & & & & + & \\
\hline Clonazepam & & & & & & & & & & + & + & & & & \\
\hline Benzodiaz. & & & & & & & & & & & & & + \\
\hline
\end{tabular}

Table 2. Combinations of three and more AEDs used in the group of patients with epilepsy.

The relation of seizures and sleep or waking state was examined in all patients suffering from epilepsy. On this basis, patients were divided into two groups. The first group of 17 patients had seizures between 10.00 p.m. and 7.00 a.m. which means during sleep or on awakening. The second group of 83 patients had predominantly or exclusively seizures related to waking hours.

\subsection{Characteristics of the control group}

Control group was composed by 80 healthy persons without anamnesis of epilepsy. They were admitted to the I. Neurology Clinic of Comenius University Hospital in Bratislava for low back pain and in time of evaluation were without pain, which could interfere with sleep. The group consisted of 45 women and 35 men with everage age 38,75 $\pm 14,32$ year, including 17 - 78 years.

\section{Stastistical methods}

The standard box-and-whisker plots were used for graphical representation of the parameter distribution in the particular groups of patients (Rousseeuw et al., 1999). Normality of data was verified by the Lilliefors test (Conover, 1999). To compare the observed parameters, the parametric method unpaired Student's group t-test was used 
(Kirkwood, 2003; Dušek, 2009). As the non-parametric statistical methods we used the Kruskal - Wallis H test and the Kolmogorov-Smirnov test. (Gibbons and Subhabrata, 2003)

\section{Results}

\subsection{Changes in daytime sleepiness}

Mean value of ESS in the group of patients with epilepsy was 7,11 $\pm 4,54$, in control group $5,53 \pm 2,15$. Both mean values were in physiological range (under 9). Through that mean value of ESS was higher in group with epilepsy and the difference against control group was significant on $\mathrm{p}<0,05$ confirmed by all three used stastistical methods (see figure 4 , table 3,4 ). This result is assesed as significant tendency to daytime sleepiness in patients with epilepsy.

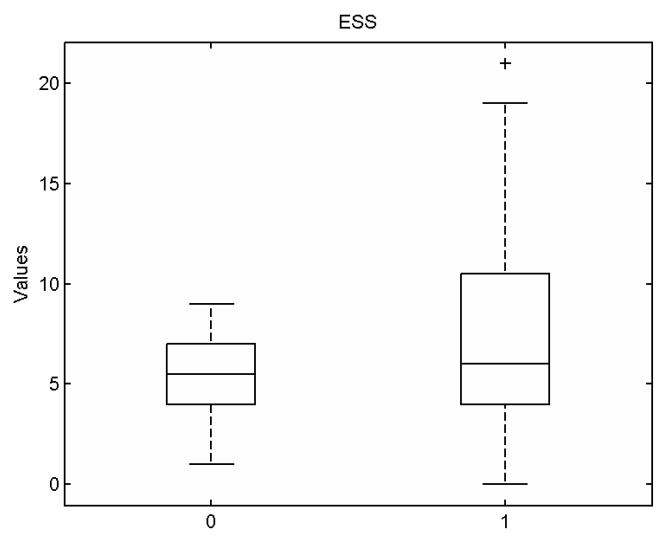

Fig. 4. Values of score Epworth Scale of Sleepiness (ESS) in the control group (0) and in the group of patients with epilepsy (1). The difference is statistically significant $(p<0,05)$.

\begin{tabular}{|l|c|c|c|c|c|c|c|}
\hline & nubmer & Mean value & SD & $\begin{array}{c}\text { Min } \\
\text { value }\end{array}$ & $\begin{array}{c}\text { Max } \\
\text { value }\end{array}$ & Median & $\begin{array}{c}\text { Lilliefors } \\
\text { test (p) }\end{array}$ \\
\hline $\begin{array}{l}\text { ESS } \\
\text { control } \\
\text { group }\end{array}$ & 80 & 5,53 & 2,15 & 1 & 9 & 5,5 & 0,003488 \\
\hline $\begin{array}{l}\text { ESS } \\
\text { Epilep. }\end{array}$ & 100 & 7,11 & 4,54 & 0 & 21 & 6,0 & 0,001938 \\
\hline
\end{tabular}

Table 3. Values of score ESS and statistical parameters in cotrol group and group of patients with epilepsy.

\begin{tabular}{|c|c|c|c|}
\hline & t-test & Kruskal-Wallis & Kolmogorov-Smirnov \\
\hline $\mathrm{p}$ & $\mathbf{0 , 0 0 2 6 1 2 2 6 ^ { * }}$ & $\mathbf{0 , 0 4 7 1 2 3 4 6 9 ^ { * }}$ & $\mathbf{0 , 0 0 0 1 5 2 9 1 5 ^ { * }}$ \\
\hline
\end{tabular}

Table 4. Statistical comparison of values ESS by Students t-test, Kruskal-Wallis test a Kolmogorov-Smirnovov test. All result are statistically significant. 


\subsection{Changes in sleep architecture}

In control group and group of patients with epilepsy statistical parameters as effectivity of sleep, amount of NREM S1, S2, S3+4, REM, latency to NREM S1 and latency to REM sleep were evaluated. Normality of distribution of data was tested by Lilliefors test and tests like Student's t-test, Kruskal-Wallis test and Kolmogor-Smirnov test were used (see tables 5a, $5 b, 5 c)$

\begin{tabular}{|l|c|c|c|c|c|c|c|}
\hline & nubmer & average & SD & $\begin{array}{c}\text { Min } \\
\text { value }\end{array}$ & $\begin{array}{c}\text { Max } \\
\text { value }\end{array}$ & Median & $\begin{array}{c}\text { Lilliefors } \\
\text { (p) }\end{array}$ \\
\hline $\begin{array}{l}\text { Eff. of } \\
\text { sleep /\%/ }\end{array}$ & 80 & 87,38 & 9,89 & 50 & 99 & 90,5 & 0,001 \\
\hline S1/\%/ & 80 & 26,39 & 12,62 & 1,4 & 60,7 & 25,2 & 0,5 \\
\hline S2 /\%/ & 80 & 29,40 & 10,10 & 12,3 & 49,9 & 28,7 & 0,14 \\
\hline S3,S4/\%/ & 80 & 21,02 & 9,34 & 0,1 & 48,9 & 19,35 & 0,002 \\
\hline REM/\%/ & 80 & 23,06 & 9,96 & 0 & 47,8 & 24,95 & 0,02 \\
\hline $\begin{array}{l}\text { Lat. to S1 } \\
\text { /min/ }\end{array}$ & 80 & 27,58 & 28,18 & 2 & 123,5 & 15,5 & 0,001 \\
\hline $\begin{array}{l}\text { Lat. to } \\
\text { REM/min/ }\end{array}$ & 79 & 132,64 & 67,04 & 21,5 & 372 & 118 & 0,001 \\
\hline
\end{tabular}

(SD - standard deviation)

Table 5a. Descriptive characteristics in the control group

\begin{tabular}{|l|c|c|c|c|c|c|c|}
\hline & nubmer & average & SD & Min value & Max value & Median & $\begin{array}{c}\text { Lilliefors } \\
\text { (p) }\end{array}$ \\
\hline $\begin{array}{l}\text { Eff. of } \\
\text { sleep /\%/ }\end{array}$ & 100 & 77,10 & 15,06 & 30 & 98 & 80 & 0,001 \\
\hline S1 /\%/ & 99 & 22,75 & 11,29 & 1,3 & 48,5 & 21 & 0,34 \\
\hline S2 /\%/ & 100 & 38,77 & 12,83 & 12,8 & 68,9 & 36,55 & 0,17 \\
\hline S3,S4/\%/ & 100 & 19,13 & 9,28 & 0,23 & 43 & 17,95 & 0,003 \\
\hline REM /\%/ & 100 & 18,82 & 9,06 & 1,9 & 54,3 & 18,05 & 0,30 \\
\hline $\begin{array}{l}\text { Lat. to S1 } \\
\text { /min/ }\end{array}$ & 100 & 41,55 & 60,23 & 1,5 & 386,5 & 20,5 & 0,001 \\
\hline $\begin{array}{l}\text { Lat. to } \\
\text { REM } \\
\text { /min/ }\end{array}$ & 98 & 163,26 & 94,75 & 33 & 454,5 & 137 & 0,001 \\
\hline
\end{tabular}

(SD - standard deviation)

Table 5b. Descriptive characteristics in the group of patients with epilepsy 


\begin{tabular}{|l|c|c|c|}
\hline & $\begin{array}{c}\mathrm{t}-\text { Test } \\
(\mathrm{p})\end{array}$ & $\begin{array}{c}\text { Kruskal-Wallis } \\
(\mathrm{p})\end{array}$ & $\begin{array}{c}\text { Kolmogorov-Smirnov } \\
(\mathrm{p})\end{array}$ \\
\hline Eff. of sleep /\%/ & $\mathbf{1 , 3 5 0 9 \mathrm { E } - 0 7 ^ { * }}$ & $\mathbf{6 , 2 3 4 0 4 \mathrm { E } - 0 7 ^ { * }}$ & $\mathbf{3 , 8 4 7 7 3 \mathrm { E } - 0 5 ^ { * }}$ \\
\hline S1 /\%/ & 0,046 & 0,066 & 0,230 \\
\hline S2 /\%/ & $\mathbf{1 , 4 2 6 3 9 \mathrm { E } - 0 7 ^ { * }}$ & $\mathbf{1 , 2 9 3 3 4 \mathrm { E } - 0 6 ^ { * }}$ & $\mathbf{1 , 0 4 3 2 1 \mathrm { E } - 0 5 ^ { * }}$ \\
\hline S3,S4/\%/ & 0,179 & 0,163 & 0,304 \\
\hline REM /\%/ & $\mathbf{0 , 0 0 4 ^ { * }}$ & $\mathbf{0 , 0 0 1 ^ { * }}$ & $\mathbf{0 , 0 0 0 8 ^ { * }}$ \\
\hline Lat. to S1/min/ & 0,042 & 0,346 & 0,346 \\
\hline Lat. to REM /min/ & $\mathbf{0 , 0 1 3 ^ { * }}$ & $\mathbf{0 , 0 4 7 ^ { * }}$ & $\mathbf{0 , 0 0 4 ^ { * }}$ \\
\hline
\end{tabular}

Table 5c. Comparison of observed characteristics in the control group and in the group of patients with epilepsy

Patients with epilepsy have significantly lower effectivity of sleep than healthy controls on statistical significance $p<0,001^{*}$ (see figure 5a). Furthermore patients with epilepsy have significantly more NREM S2 sleep, fewer REM sleep and have significantly longer latency to first REM sleep in comparison to healthy controls (see figures $5 b, 5 C, 5 d$ ). Other differences were not significant.

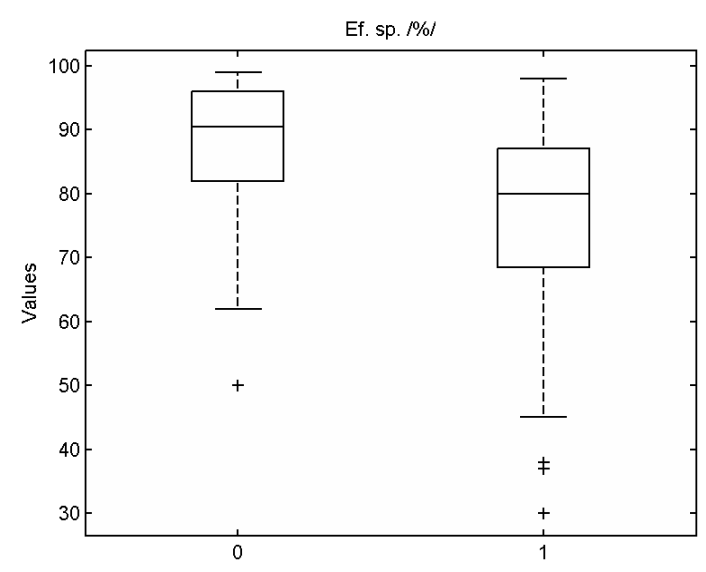

Fig. 5a. Effecitvity of sleep in the control group (0) and in the group of patients with epilepsy (1). The difference is statistically significant $(p<0,001)$.

Significant changes in sleep architecture of patients with epilepsy were observed. Lower effectivity of sleep together with higher amount of NREM S2 sleep and fewer REM sleep may have considerable consequences on quality of life of patients with epilepsy. 


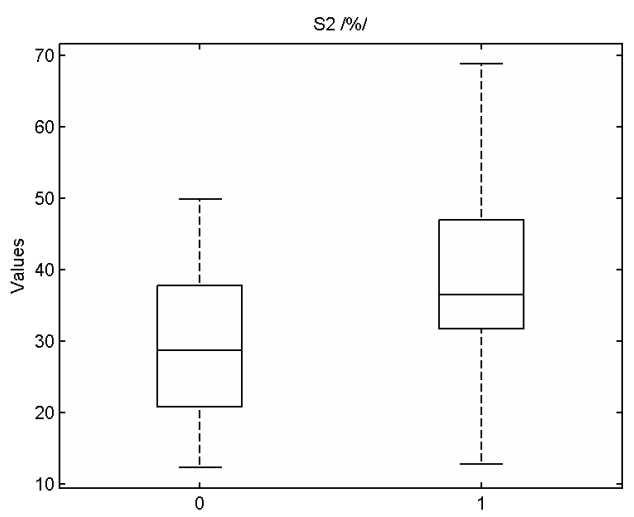

Fig. 5b. Value of NREM S2 (\%) in the control group (0) and in the group of patients with epilepsy (1). The difference is statistically significant $(p<0,001)$.
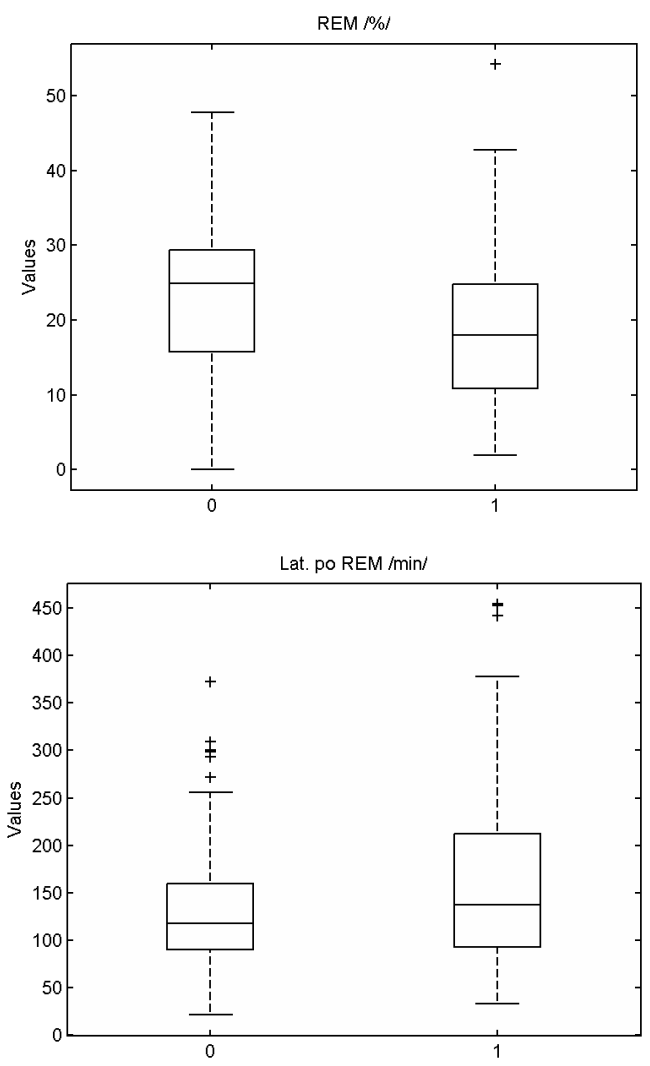

Fig. 5c., 5d. Value of REM (\%) and latency to REM sleep (minutes) in the control group (0) and in the group of patients with epilepsy (1). The differences are statistically significant. 


\subsection{Evaluation of factors with possible influence on sleep architecture of patients with epilepsy}

Some characteristics of epilepsy, like type of epilepsy, it's etiology, antiepileptic medication, actual compensation of seizures or evidence of ictal discharges may have influence on quality of sleep. We have chosen some of these factors with purpose to try to find reasons of different characteristics of sleep in patients with epilepsy. Parameters of ESS, MSLT and sleep macroarchitecture were evaluated and statistically compared.

\subsubsection{Influence of antiepileptic medication on daytine sleepiness and architecture of sleep}

All patients with epilepsy in monitored group were treated by AEDs. As the first step 55 patients with monotherapy AEDs were evaluated. In this group 14 patients were treated by valproate, 31 patients by carbamazepine and 10 patients by lamotrigine. Parameters of ESS, MSLT, effectivity of sleep, \% portions of sleep stages NREM S1, S2, S3+4, REM sleep and latency to NREM S1 sleep and latency to REM sleep were examined and statistically compared. No significant differences were ascertained, only patients treated by carbamazepine had higher score of ESS, more \% portion of S1 NREM stage, less \% portion of deep S3+S4 NREM sleep and had longer latency to first REM stage in comparison with patients treated only by valproate or lamotrigine (see figures $6 a, 6 b, 6 c$ and $6 d$ ). These results may indicate some negative effect of carbamazepine on quality of daytime vigility and sleep.

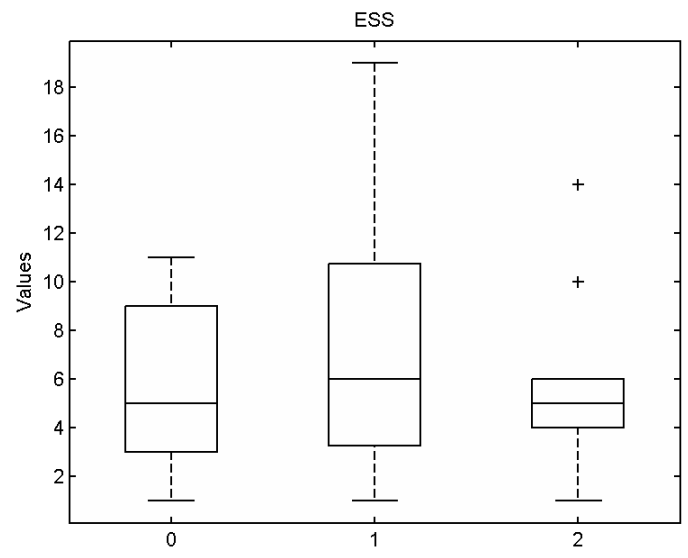

Fig. 6a. Values of ESS in the group of patients with valproate (0), carbamazepine (1) and lamotrigine (2). Differences are not statistically significant.

As the next step, characteristics of daytime sleepiness and quality of sleep in the group of patients with monotherapy and the group of patients on two and more AEDs were evaluated and compared. We supposed, that combination of two and more AEDs could disturb night sleep and worsten daytime vigility. Group of patients using monotherapy consisted of 55 parients, in next group with more AEDs were 45 patients. Observed parameters are presented in tables $6 a, 6 b$. 

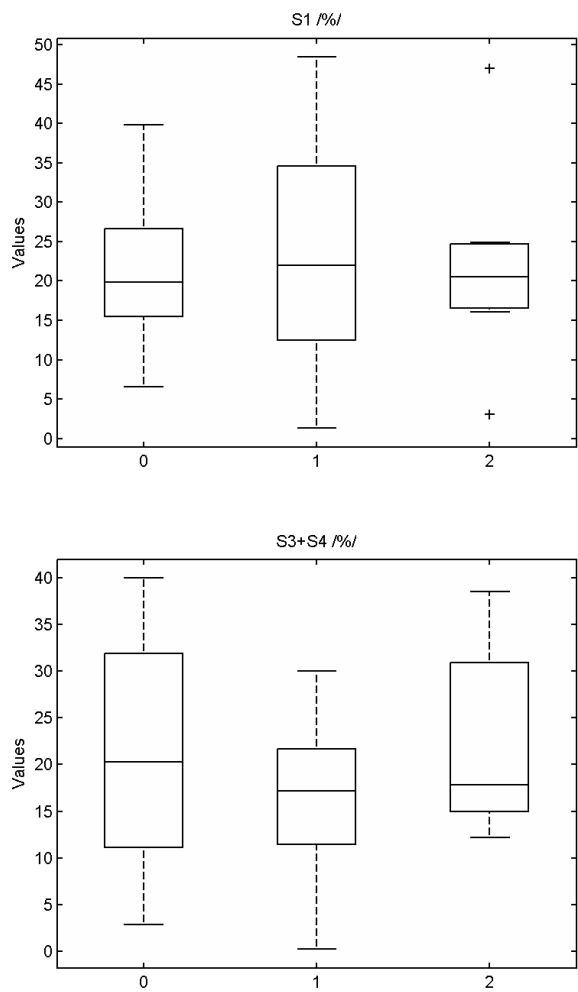

Fig. 6b., 6c. Portion of S1 NREM sleep and S3+S4 NREM sleep in the group of patients with valproate (0), carbamazepine (1) and lamotrigine (2). Differences are not statistically significant.

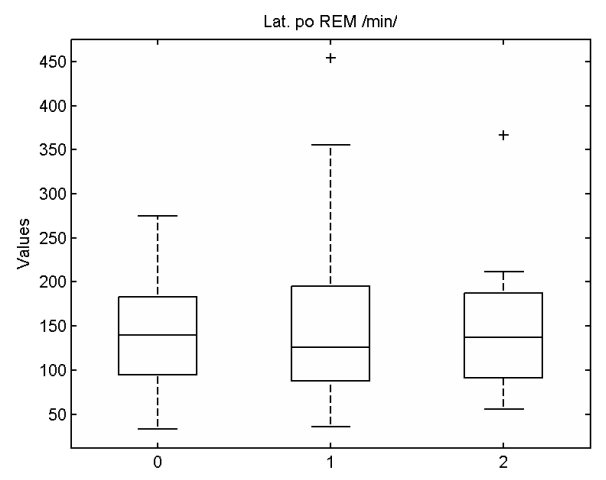

Fig. 6d. Latency to first REM sleep in the group of patients with valproate (0), carbamazepine (1) and lamotrigine (2). Differences are not statistically significant. 


\begin{tabular}{|l|c|c|c|c|c|c|c|}
\hline & number & mean & SD & $\begin{array}{c}\text { Min } \\
\text { value }\end{array}$ & $\begin{array}{c}\text { Max } \\
\text { value }\end{array}$ & Median & $\begin{array}{c}\text { Lilliefors } \\
\text { test (p) }\end{array}$ \\
\hline ESS & 55 & 6,58 & 4,36 & 1 & 19 & 6 & 0,001 \\
\hline $\begin{array}{l}\text { MSLT } \\
\text { /min/ }\end{array}$ & 38 & 12,87 & 5,18 & 3,2 & 20 & 14,1 & 0,09 \\
\hline $\begin{array}{l}\text { Eff. of } \\
\text { sleep /\%/ }\end{array}$ & 55 & 76,45 & 15,08 & 30 & 98 & 79 & 0,012 \\
\hline S1/\%/ & 55 & 22,99 & 11,45 & 1,3 & 48,5 & 20,8 & 0,039 \\
\hline S2/\%/ & 55 & 38,39 & 13,29 & 15,3 & 67,9 & 36,7 & 0,5 \\
\hline $\begin{array}{l}\text { S3+S4 } \\
\text { /\%/ }\end{array}$ & 55 & 18,50 & 9,63 & 0,23 & 40 & 17,3 & 0,23 \\
\hline REM /\%/ & 55 & 19,75 & 9,79 & 1,9 & 54,3 & 20 & 0,40 \\
\hline $\begin{array}{l}\text { Lat. to S1 } \\
\text { /min/ }\end{array}$ & 55 & 40,12 & 58,08 & 1,5 & 386,5 & 18,5 & 0,001 \\
\hline $\begin{array}{l}\text { Lat. to } \\
\text { REM } \\
\text { /min/ }\end{array}$ & 55 & 161,38 & 90,79 & 33 & 454,5 & 139,5 & 0,002 \\
\hline
\end{tabular}

(SD -standard deviation)

Table 6a. Descriptive characteristics of patients with monotherapy of antiepileptic drugs.

\begin{tabular}{|l|c|c|c|c|c|c|c|}
\hline & number & mean & SD & $\begin{array}{c}\text { Min } \\
\text { value }\end{array}$ & $\begin{array}{c}\text { Max } \\
\text { value }\end{array}$ & Median & $\begin{array}{c}\text { Lilliefors } \\
\text { test (p) }\end{array}$ \\
\hline ESS & 45 & 7,88 & 4,73 & 0 & 21 & 8 & 0,46 \\
\hline MSLT & 33 & 12,9 & 5,15 & 3,1 & 20 & 13,6 & 0,30 \\
\hline $\begin{array}{l}\text { Ef.sp. } \\
\text { /\%/ }\end{array}$ & 45 & 78,02 & 15,17 & 38 & 98 & 81 & 0,05 \\
\hline S1/\%/ & 45 & 22,39 & 11,20 & 1,6 & 46,6 & 23,3 & 0,23 \\
\hline S2/\%/ & 45 & 39,33 & 12,28 & 12,8 & 68,9 & 36,4 & 0,14 \\
\hline $\begin{array}{l}\text { S3+S4 } \\
\text { /\%/ }\end{array}$ & 45 & 20,04 & 8,79 & 7,9 & 43 & 18,7 & 0,002 \\
\hline $\begin{array}{l}\text { REM } \\
\text { /\%/ }\end{array}$ & 45 & 17,49 & 7,80 & 7,4 & 32,7 & 15,7 & 0,22 \\
\hline $\begin{array}{l}\text { Lat.po } \\
\text { S1 } \\
\text { /min/ }\end{array}$ & 45 & 43,61 & 63,88 & 2 & 386,5 & 23,5 & 0,001 \\
\hline $\begin{array}{l}\text { Lat.po } \\
\text { REM } \\
\text { /min/ }\end{array}$ & 45 & 165,88 & 101,08 & 49 & 453 & 125 & 0,001 \\
\hline
\end{tabular}

(SD -standard deviation)

Table $6 \mathrm{~b}$. Descriptive characteristics of patients with therapy of two and more AEDs. 
Table 6c shows statistical comparison of evaluated parameters in both groups. Differences are not significant.

\begin{tabular}{|l|c|c|c|}
\hline & $\begin{array}{c}\text { t-Test } \\
(\mathbf{p})\end{array}$ & $\begin{array}{c}\text { Kruskal-Wallis } \\
(\mathbf{p})\end{array}$ & $\begin{array}{c}\text { Kolmogor-Smirnov } \\
(\mathbf{p})\end{array}$ \\
\hline ESS & 0,17 & 0,12 & 0,06 \\
\hline MSLT & 0,98 & 0,96 & 0,10 \\
\hline Eff. of sleep /\%/ & 0,61 & 0,49 & 0,90 \\
\hline NREM S1 /\%/ & 0,79 & 0,88 & 0,72 \\
\hline NREM S2/\%/ & 0,72 & 0,96 & 0,57 \\
\hline NREM S3+S4/\%/ & 0,41 & 0,50 & 0,66 \\
\hline REM /\%/ & 0,20 & 0,29 & 0,28 \\
\hline Lat. to S1/min/ & 0,78 & 0,63 & 0,63 \\
\hline Lat. to REM /min/ & 0,82 & 0,10 & 0,89 \\
\hline
\end{tabular}

Table 6c. Comparison of observed parameters in the group of patients on monotherapy and the group with two and more AEDs.

Though patients in the group with combination of AEDs have lightly elevated score ESS (ESS 7,88 $\pm 4,74$ ) in comparison of patients on monotherapy (ESS 6,58 $\pm 4,36$ ), the difference was not significant (see figure 7). Neither of other evaluated differences was significantly different.

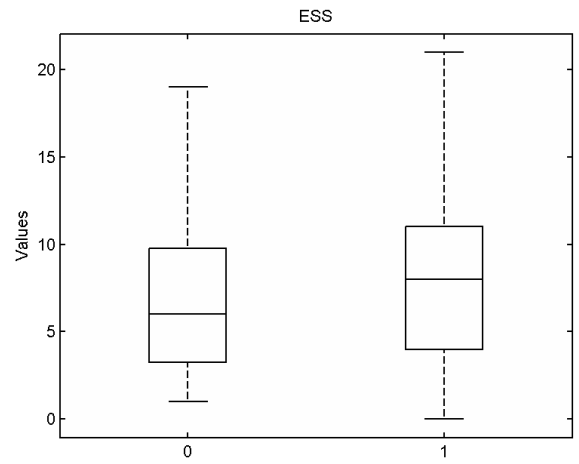

Fig. 7. Values of ESS in the group with monotperapy (0) and the group with two and more AEDs (1). The difference is not significant.

\subsubsection{Influence of type of epilepsy (focal/generalized) on daytime sleepiness and quality of sleep}

Epileptogenesis of focal and generalized epilepsy is diverse. In focal epilepsy epileptic discharge is localizated and placement of epileptic focus is important as well as possible secondary generalization. Primary generalized epilepsies have different mechanism of epileptigenesis with involvement of bigger areas of the brain. It was expected, that focal and 
generalized epilepsies have also different influence on sleep architecture. Group of 100 patients with epilepsy was divided in two groups. Group of patients with focal epilepsy inclosed 76 patients, in group of generalized epilepsy were 24 patients. Tables $7 \mathrm{a}, 7 \mathrm{~b}$ and $7 \mathrm{c}$ describe results of ESS, MSLT, effectivity of sleep and other characteristics of sleep.

\begin{tabular}{|l|c|c|c|c|c|c|c|}
\hline & number & mean & SD & Min value & Max value & Median & $\begin{array}{c}\text { Lilliefors test } \\
\text { (p) }\end{array}$ \\
\hline ESS & 76 & 7,22 & 4,50 & 0 & 21 & 6 & 0,008 \\
\hline MSLT & 56 & 12,64 & 5,02 & 3,1 & 20 & 13,15 & 0,30 \\
\hline $\begin{array}{l}\text { Eff. of } \\
\text { sleep /\%/ }\end{array}$ & 76 & 78,60 & 13,78 & 38 & 98 & 81 & 0,007 \\
\hline S1/\%/ & 75 & 23,88 & 11,54 & 1,3 & 48,5 & 22,9 & 0,5 \\
\hline S2/\%/ & 76 & 39,34 & 12,88 & 12,8 & 68,9 & 36,95 & 0,14 \\
\hline S3+S4/\%/ & 76 & 17,80 & 8,61 & 0,23 & 43 & 17,1 & 0,006 \\
\hline REM /\%/ & 76 & 18,79 & 9,55 & 1,9 & 54,3 & 17,45 & 0,37 \\
\hline $\begin{array}{l}\text { Lat. to S1 } \\
\text { /min/ }\end{array}$ & 76 & 36,67 & 52,87 & 1,5 & 386,5 & 18,5 & 0,001 \\
\hline $\begin{array}{l}\text { Lat. to } \\
\text { REM } \\
\text { /min/ }\end{array}$ & 75 & 165,61 & $\begin{array}{c}101,0 \\
5\end{array}$ & 36 & 454,5 & 125 & 0,001 \\
\hline
\end{tabular}

Table 7a. Descriptive characteristics of group with focal epilepsy.

\begin{tabular}{|l|c|c|c|c|c|c|c|}
\hline & numbert & mean & SD & Min value & Max value & Median & $\begin{array}{c}\text { Lilliefors test } \\
\text { (p) }\end{array}$ \\
\hline ESS & 24 & 6,75 & 4,73 & 0 & 15 & 5,5 & 0,05 \\
\hline MSLT & 15 & 13,79 & 5,59 & 3,2 & 20 & 15 & 0,05 \\
\hline $\begin{array}{l}\text { Eff.of } \\
\text { sleep /\%/ }\end{array}$ & 24 & 72,32 & 18,07 & 30 & 98 & 76,5 & 0,45 \\
\hline S1/\%/ & 24 & 19,22 & 9,89 & 3,1 & 39,8 & 19,9 & 0,50 \\
\hline S2/\%/ & 24 & 36,97 & 12,77 & 15,3 & 57,4 & 35,65 & 0,50 \\
\hline S3+S4/\%/ & 24 & 23,35 & 10,23 & 2,5 & 40 & 21,9 & 0,33 \\
\hline REM & 24 & 18,92 & 7,47 & 6,9 & 34,8 & 19,1 & 0,50 \\
\hline $\begin{array}{l}\text { Lat. to S1 } \\
\text { /min/ }\end{array}$ & 24 & 57 & 78,58 & 3 & 386,5 & 36,75 & 0,001 \\
\hline $\begin{array}{l}\text { Lat. to } \\
\text { REM } \\
\text { /min/ }\end{array}$ & 23 & 155,61 & 71,81 & 33 & 333 & 139,5 & 0,05 \\
\hline
\end{tabular}

Table $7 \mathrm{~b}$. Descriptive characteristics of group with primary generalized epilepsy. 


\begin{tabular}{|l|c|c|c|}
\hline & $\begin{array}{c}\text { t-test } \\
(\mathbf{p})\end{array}$ & $\begin{array}{c}\text { Kruskal-Wallis } \\
(\mathbf{p})\end{array}$ & $\begin{array}{c}\text { Kolmogor-Smirnov } \\
(\mathbf{p})\end{array}$ \\
\hline ESS & 0,67 & 0,61 & 0,89 \\
\hline MSLT & 0,48 & 0,37 & 0,45 \\
\hline Eff. of sleep /\%/ & $\mathbf{0 , 0 2 *}$ & $\mathbf{0 , 0 1 *}$ & $\mathbf{0 , 0 0 5 ^ { * }}$ \\
\hline NREM S1/\%/ & 0,06 & 0,10 & 0,43 \\
\hline NREM S2 /\%/ & 0,43 & 0,50 & 0,36 \\
\hline NREM S3+S4/\%/ & $\mathbf{0 , 0 2 *}$ & $\mathbf{0 , 0 1 *}$ & $\mathbf{0 , 0 0 8 ^ { * }}$ \\
\hline REM /\%/ & 0,94 & 0,69 & 0,82 \\
\hline Lat. to S1/min/ & 0,24 & 0,09 & 0,16 \\
\hline Lat. to REM /min/ & 0,61 & 0,74 & 0,42 \\
\hline
\end{tabular}

Table 7c. Comparison of observed parameters in the group with focal epilepsy and the group with generalized epilepsy.

It was detected, that patients with generalized epilepsy have lower effectivity of sleep and patients with focal epilepsy have fewer deep sleep stages of NREM sleep. These differences are statistically significant. Figures $8 \mathrm{a}, 8 \mathrm{~b}$ show these results.

This may be result of different mechanism of epileptogenesis in both types of epilepsy, though further study should be done to exlpain these differences.

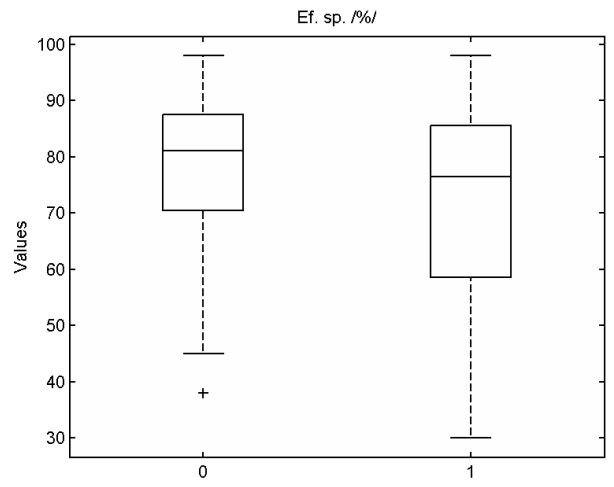

Fig. 8a. Effectivity of sleep in the group of focal epilepsy (0) and the group of generalized epilepsy (1). The difference is statistically significant. 


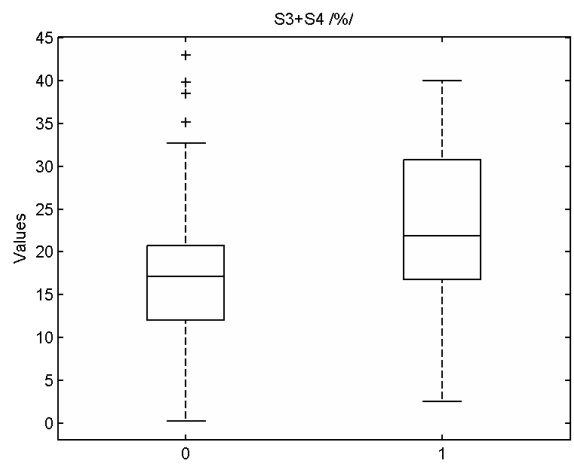

Fig. 8b. Portion of S3+S4 NERM sleep in the group of focal epilepsy (0) and the group of generalized epilepsy (1). The difference is statistically significant.

\subsubsection{Influence of localization of epileptic focus on daytime sleepiness and architecture of sleep}

Localization of epileptic focus in the group of patients with focal epilepsy was determined by EEG evaluation. Correct localization of epileptic focus was possible by 72 patients. The rest of patients had multiple foci or normal EEG.

Group of 72 patients was divided into two parts. In the first group 61 patients had focus in temporal or temporoparietal region. Next group of 11 patients had focus in frontal or frontotemporal region. Characteristics of daytime vigility and night sleep were compared in both groups. Results are presented in tables $8 \mathrm{a}, 8 \mathrm{~b}$ and $8 \mathrm{c}$.

\begin{tabular}{|l|c|c|c|c|c|c|c|}
\hline & Number & Mean & SD & Min value & Max value & Median & $\begin{array}{c}\text { Lilliefors } \\
\text { test (p) }\end{array}$ \\
\hline ESS & 61 & 7,28 & 4,39 & 0 & 19 & 6 & 0,02 \\
\hline MSLT & 44 & 12,20 & 4,84 & 4,5 & 20 & 11,9 & 0,42 \\
\hline $\begin{array}{l}\text { Eff. of } \\
\text { sleep /\%/ }\end{array}$ & 61 & 78,36 & 13,49 & 38 & 98 & 81 & 0,002 \\
\hline S1 /\%/ & 60 & 23,34 & 11,83 & 1,3 & 48,5 & 21,9 & 0,50 \\
\hline S2 /\%/ & 61 & 39,21 & 13,03 & 12,8 & 68,9 & 36,7 & 0,14 \\
\hline $\begin{array}{l}\text { S3+S4 } \\
\text { /\%/ }\end{array}$ & 61 & 17,84 & 8,90 & 0,23 & 43 & 16,9 & 0,002 \\
\hline REM /\%/ & 61 & 19,40 & 9,86 & 1,9 & 54,3 & 18,8 & 0,50 \\
\hline $\begin{array}{l}\text { Lat. to S1 } \\
\text { /min/ }\end{array}$ & 61 & 38,09 & 56,28 & 1,5 & 386,5 & 19,5 & 0,001 \\
\hline $\begin{array}{l}\text { Lat. to } \\
\text { REM } \\
\text { /min/ }\end{array}$ & 60 & 163,59 & 97,35 & 36 & 454,5 & 135 & 0,007 \\
\hline
\end{tabular}

(SD -standard deviation)

Table 8a. Descriptive characteristisc of group with temporal, or temporoparietal focus. 


\begin{tabular}{|l|c|c|c|c|c|c|c|}
\hline & Number & Mean & SD & Min value & Max value & Median & $\begin{array}{c}\text { Lilliefors } \\
\text { test (p) }\end{array}$ \\
\hline ESS & 11 & 7,54 & 5,25 & 1 & 21 & 7 & 0,48 \\
\hline MSLT & 9 & 14,27 & 5,57 & 3,1 & 20 & 15,25 & 0,03 \\
\hline $\begin{array}{l}\text { Eff. of } \\
\text { sleep } \\
\text { /\%/ }\end{array}$ & 11 & 79,08 & 15,47 & 50 & 98 & 79 & 0,22 \\
\hline S1/\%/ & 11 & 26,32 & 9,63 & 11,6 & 40 & 24,9 & 0,50 \\
\hline S2/\%/ & 11 & 41,02 & 12,90 & 15,9 & 67,9 & 37,8 & 0,39 \\
\hline $\begin{array}{l}\text { S3+S4 } \\
\text { /\%/ }\end{array}$ & 11 & 17,13 & 8,05 & 1,1 & 30,6 & 17,1 & 0,50 \\
\hline $\begin{array}{l}\text { REM } \\
\text { /\%/ }\end{array}$ & 11 & 15,47 & 7,87 & 5,1 & 32,7 & 15 & 0,50 \\
\hline $\begin{array}{l}\text { Lat. to } \\
\text { S1/min/ }\end{array}$ & 11 & 25,50 & 25,74 & 1,5 & 97 & 17 & 0,07 \\
\hline $\begin{array}{l}\text { Lat. to } \\
\text { REM } \\
\text { /min/ }\end{array}$ & 11 & 164,39 & 114,51 & 36 & 378 & 112,5 & 0,03 \\
\hline
\end{tabular}

Table $8 \mathrm{~b}$. Descriptive characteristisc of group with frontal of frontotemporal focus.

\begin{tabular}{|l|c|c|c|}
\hline & $\begin{array}{c}\text { t-test } \\
(\mathbf{p})\end{array}$ & $\begin{array}{c}\text { Kruskal-Wallis } \\
(\mathbf{p})\end{array}$ & $\begin{array}{c}\text { Kolmogor-Smirnov } \\
(\mathbf{p})\end{array}$ \\
\hline ESS & 0,87 & 0,98 & 0,99 \\
\hline MSLT & 0,26 & 0,19 & $\mathbf{0 , 0 4}$ \\
\hline Ef.sp./\%/ & 0,88 & 0,93 & 0,77 \\
\hline S1/\%/ & 0,34 & 0,28 & 0,66 \\
\hline S2/\%/ & 0,65 & 0,53 & 0,51 \\
\hline S3+S4/\%/ & 0,78 & 0,96 & 0,96 \\
\hline REM /\%/ & 0,13 & 0,19 & 0,52 \\
\hline Lat. to S1/min/ & 0,22 & 0,68 & 0,76 \\
\hline Lat. to REM /min/ & 0,98 & 0,80 & 0,94 \\
\hline
\end{tabular}

Table 8c. Comparison of observed parameters in the group with temporal or temporoparietal focus and the group with frontal or frontotemporal focus.

Kolmogov-Smirnov test showed significant difference in mean latency of sleep by MSLT as patients with temporal or temporoparietal focus have significantly shorter time in MSLT in comparison with group of patients with frontal or frontotemporal focus (see figure 9). Though medians of both MSLT tests are in normal range ( $>10$ minutes), distribution of datas in the group with temporal and temporoparietal localization of focus is more disperzed as well as values of short mean latency are presented. This may indicate some tendency to elevated daytime sleepiness in the group of patients with temporal or temporoparietal localization of epileptic focus. 


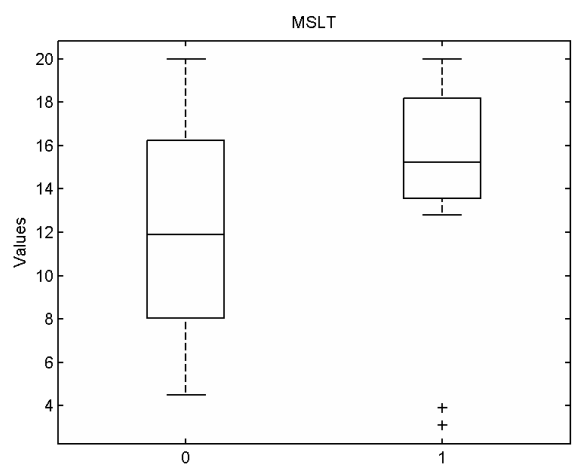

Fig. 9. Mean values of latencies in MSLT in the group with temporal or temporoparietal focus (0) and in the group with frontal and frontotemporal focus (1). The difference is significant.

\section{Discussion}

Patients in our study as well as control group didn't have elevated daytime sleepiness according to results of Epworth scale of sleepiness (ESS). This result is in accordance with literature, where ESS of epileptic patients and healthy controls did not differ significantly (Malow et al., 1997; Manni et al., 2000; Watanabe et al., 2003). Patients with epilepsy in our group had significantly higher score of ESS than control group. This result was assessed as tendency to daytime sleepiness in patients with epilepsy.

Reason of tendency to problems with vigility in epileptic patients is probably multifactorial. We suppose that detemining cause is fragmentation of sleep architecture with failure of its restorative functions. We found out significant changes in sleep architecture of epileptic patients, which correlate with literature data (Bazil, 2003; Niedermeyer, 1982; Sammaritano et al., 1994; Touchon et al., 1991), as significantly lower effectivity of sleep, significantly more NREM S2 stage sleep, fewer REM sleep and longer latency to REM sleep. According to literature these changes are caused by epileptic seizures, antiepileptic therapy and severity of epilepsy (Bazil, Malow \& Sammaritano, 2002). We did not prove influence of antiepileptic therapy on quality of sleep and daytime vigility. This might be influenced by that patients were using medication for longer time before evaluation. Further evaluation should be done in this area to determine influence of specific antiepileptic drugs on sleep architecture.

According to different mechanizms of epileptogenesis in focal and generalized epilepsies various centers of brain involved in regulation of sleep may be influenced (Faber, 1995). This probably correlates with our results of significant reduction of S3 and S4 NREM sleep in the group of patients with focal epilepsy and significant decrement of effectivity of sleep in patients with generalized epilepsy. Changes of sleep in focal epilepsy are probably influenced by localization and ethiology of laesion, in generalized epilepsy thalamocortical circuits involved in epileptogenesis probably influence wider areas of brain.

That is why localization of epileptic focus was also evaluated in correlation with daytime sleepiness and quality of sleep. Significantly shorter mean latency in MSLT was detected in patients with temporal focus in comparison with patients with extratemporal epileptic focus. 
Similar results were published by De Almeida et al. (2003), who referred that patients with temporal lobar epilepsy have fragmentation of sleep and reduction of REM sleep.

\section{Conclusion}

Significant changes in sleep architecture of patients with epilepsy were observed, as lower effectivity of sleep together with higher amount of NREM S2 sleep and fewer REM sleep. These may negatively influence daytime vigility, mental abilities and also compensation of epilepsy.

It was also detected, that patients with generalized epilepsy have lower effectivity of sleep and patients with focal epilepsy have fewer deep sleep stages of NREM sleep.

Some tendency to elevated daytime sleepiness in the group of patients with temporal or temporoparietal localization of epileptic focus was proved.

We recommend awareness among clinicians of the comorbidity of epilepsy and sleep disorders as correct diagnostic and therapeutic approach may improve quality of life of patients.

\section{Acknowledgement}

This article was published with support of UCB s.r.o, Slovakia.

\section{References}

American Sleep Disorders Association: The clinical use of the Multiple sleep latency test. Sleep,Vol.15, No.3, (Mar., 1992), pp. 268-276, ISSN 0161-8105

Bazil CW. Epilepsy and sleep disturbance. Epilepsy \& Behavior, Vol.4, Supplement 2, (Oct., 2003), pp. 39-45, ISSN 1525-5050.

Bazil CW, Castro LHM, Walczak TS. (2000). Reduction of Rapid Eye Movement Sleep by Diurnal and Nocturnal Seizures in Temporal Lobe Epilepsy. Arch neurol, Vol. 57, No. 3, (Mar. 2000), pp. 363-368, ISSN ISSN:0003-9942.

Bazil CW, Malow BA, Sammaritano MR (2002). Sleep and Epilepsy:the Clinical Spectrum. Elsevier Science B.V., ISBN: 0-444-50479-6, Amstedram.

Carscadon MA, Dement WC. (1982). The multiple sleep latency test: what does measure? Sleep: Journal of Sleep research \& Sleep Medicine, vol.5, (Suppl 2, 1982), pp. 67-72. ISSN 0161-8105.

Cicolin A, Magliola U, Giordano A, Terreni A., Bucca C, Mutani R. (2006). Effects of levetiracetam on nocturnal sleep and daytime vigilance in healthy volunteers. Epilepsia, Vol. 47., No. 1, (Jan., 2006), pp.82-5, ISSN 0013-9580.

Commission report: Proposal for revised classification of epilepsies and epileptic syndromes: Commission on Classification and Terminology of the International League Against Epilepsy (1989). Epilepsia, Vol. 30., No. 4, pp. 389-399, ISSN 00139580 .

Conover W. (1999). Practical Nonparametric Statistics (3rd edition), John Wiley\&Sons, Inc., ISBN 0471160687, New York, p.45.

Dasheiff RM, Kofke WA. (2003). Primarily generalised seizures are more effective than partial seizures in arousing patients from sleep. Neurol Res. Vol. 25, No.1, (Jan., 2003), pp. 63-67. ISSN 0161-6412. 
De Almeida CA, Lins OG, Lins SG, Laurentino S, Valenca MM. (2003). Sleep disorders in temporal lobe epilepsy. Arq Neuropsiquiatr. Vol. 61, No.4, (Dec., 2003), pp. 979-987. ISSN 0004-282X

Donáth V, Karovičová M, Kuchar M, Bratský L, Pit’hová B, Sýkora P. (1996). Diagostický a terapeutický štandard epilepsie. EPI-Stop, Mediforum, Bratislava, p.17.

Dušek L, Pavlík T, Koptíková J. (2009). Analýza dat v neurologii. Česká a Slovenská neurologie a neurochirurgie, Vol. 4, No. 1, (Jan., 2009), pp. 389-393, ISSN 1210-7859.

Faber J. (1995). Epilepsie a epileptózy. Maxdorf-Jesenius, ISBN 80-85912-02-3, Praha, p.9.

Foldvary-Schaefer N.(2002). Sleep complaints and epilepsy: the role of seizures, antiepileptic drugs and sleep disorders. Journal of Clinical Neurophysiology, Vol. 19, No. 6, (Dec., 2002), pp. 514-521, ISSN 1388-2457.

Foldvary-Schaefer N, Grigg-Damberer M. (2009). Sleep and Epilepsy. Seminars in Neurology, Vol. 29, No. 4, (Jan., 2009), pp. 419-428. ISSN 0271-8235.

Garcia-Borreguero D, Larrosa O, de la Llave Y, Verger K, Masramon X, Hernandez G. (2002). Treatment of restless legs syndrome with gabapentin: a double-blind, crossover study. Neurology, Vol. 59, No. 10, (Nov.,2002), pp. 1573-1579, ISSN 10158618.

Gibbons JD, Chakraborti S. (2003). Nonparametric Statistical Inference, (4th edition), CRC Press, ISBN: 0824740521, New York.

Happe S.(2003). Excessive daytime sleepiness and sleep disturbances in patients with neurological diseases: epidemiology and management. Drugs. Vol. 63, No. 24, (Dec., 2003), pp. 2725-2737. ISSN 0012-6667.

Cho YW, Kim DH, Motamendi GK. (2011). The effect of levetiracetam monotherapy on subjective sleep quality and objective sleep parameters in patients with epilepsy: Compared with the effect of carbamazepine-CR monotherapy. Seizure. Vol. 20, (Feb., 2011), pp.-in press, ISSN 1059-1311.

Chokroverty S. (1994). Sleep Disorders Medicine: Basic Science, Technical Considerations, and Clincal Aspects. Butterworth-Heinemann, p. 27. ISBN:0-7506-9002-X. Stoneham.

Johns MW. (1991). A new method for measuring daytime sleepiness: the Epworth sleepiness scale. Sleep. Vol. 14, No. 6, (Dec.,1991), pp. 540-545, ISSN 0161-8105.

Kirkwood B.R., Sterne J.A.C. (2003). Essential Medical Statistics. Blackwell Science Ltd. 1988, Blackwell Publishing company, ISBN 0-86542-871-9, pp. 64-70, Malden, Massachusetts, USA.

Littner M, Kushida C, Wise M, et al. (2005). Practice parameters for clinical use of the Multiple Sleep Latency Test. Sleep, Vol. 28, No. 1, (Jan., 2005), pp.113-121, ISSN 0161-8105.

Malow BA, Bowes RJ, Lin X. (1997). Predictors of sleepiness in epilepsy patients. Sleep. Vol. 20, No. 12 (Dec., 1997), pp. 1105-1110, ISSN 0161-8105.

Manni R, Politini L, Sartori I et al. (2000). Daytime sleepiness in epilepsy patients: evaluation by means of the Epworth sleepiness scale. J Neurol., Vol. 247, No. 9, (Apr., 2000), pp. 716-17. ISSN 0340-5354.

Manni R, Terzahgi M. (2010). Comorbidity between epilepsy and sleep disorders. Epilepsy Research, Vol.90, No.3, (May,,2010), pp.171-177, ISSN 0920-1211.

Malow BA, Levy K, Maturen K, Bowes R. (2000). Obstructive sleep apnea is common in medically refractory epilepsy patients. Neurology, Vol. 55, No. 7, (Oct.,2000), pp. 1002-1007, ISSN 0028-3878 
Marin JM, Gascon JM, Carrizos M, Gispen J. (1997). Prevalence of Sleep Apnoe Syndrome in Spanish Adult Population. International Journal of Epidemiology, Vol. 26, No. 2, (Feb.,1997), ISSN 0300-5771, pp.381-386.

Moráň M. (2003). Praktická epileptologie. Triton, p. 54, ISBN 80-7254-352-0, Brno.

Moráň M. (2005). Spánek a epilepsie. Neurol. prax, Vol.6, No.1, (Jan., 2005), pp. 45-51, ISSN 1335-9592.

Niedermeyer E. Epileptic seizure disorders. In: Bazil CW, Malow BA, Sammaritano MR. (2002). Sleep and Epilepsy:the Clinical Spectrum. Elsevier Science B.V., ISBN: 0-44450479-6, Amsterdam, p.149.

Overeem S, Readings P. (2010). Sleep Disorders in Neurology. A clinical approach. WilleyBlackwell, ISBN 978-1-4051-8843-2, Singapore, p.5.

Placidi F, Diomedi M, Scalise A, Marciani MG, Romigi A, Gigli GL. (2000). Effect of anticonvulsants on nocturnal sleep in epilepsy. Neurology, Vol. 54, No.5,Suppl 1, (Jan,2000), pp. 25-32, ISSN 0340-5354.

Rang HP, Dale MM. (1991). Pharmacology. Churchill Livongstone, ISBN 0-443-04110-5, New York, p.689.

Rechtschaffen A, Kales A. (1968). Manual of standardized terminology, techniques and scoring system for sleep stages of human subjects. NIH Publication No.204, Washington, D.C., p.2-11.

Sammaritano M, Levtova V, Samson-Dolfus D. (1994). Modifications of sleep architecture in patients with temporal lobe epilepsy. Epilepsia. Vol. 35, No. 8, (Dec., 1994), p.124, ISSN 0013-9580.

American Academy of Sleep Medicine . (2005). The International Classification of Sleep Disorders, Diagnostic and Coding Manual. Second Edition. One Westbrook Corporate Center, ISBN:0-9657220-2-3, Suite 920, Westchester, IL, 60154, USA.

Touchon J, Baldy-Moulinier M, Biliard M, Besset A, Cadhillac J. (1991). Sleep organization and epilepsy. Epilepsy Res. Suppl. 2, (1991), pp. 73-81, ISSN 0920-1211.

Rousseeuw PJ, Ida Ruts and John W. Tukey. (1994). The bagplot: A Bivariate Boxplot. The American Statistician. Vol. 53, No. 4, (Nov., 1999), pp. 382-387, ISSN 0003-1305.

Usui A, Kitahara Y, Matsushita Y, Kitajima M, Sakamoto R, Watanabe T, Motohashi N. (2008). Do you perform the multiple sleep latency test according to the guidelines? A case with multiple sleep onset REM periods. Sleep and Biological Rhytms. Vol. 6, No. 1, (Jan., 2008), pp.53-55, ISSN 1446-9235.

Watanabe M, Matsuura M, Sano T, Matsuda R, Matsuda T, Kojima T. (2003). Daytime sleepiness in hypersomniac patients, epileptic patients, and in healthy subjects. Sleep and Biological Rhytms. Vol. 1, No. 2, (June, 2003), pp. 137-138. ISSN 1446-9235.

Zucconi M. (2007). Nocturnal Frontal Lobe Epilepsy - An Update on Differential Diagnosis with Non-rapid Eye Movement Parasomnia. European neurological Disease. Issue 2, (2007), pp.62-64, ISSN: 1753-3953 


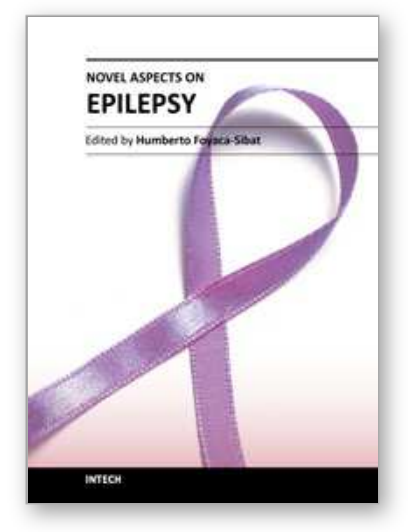

\author{
Novel Aspects on Epilepsy \\ Edited by Prof. Humberto Foyaca-Sibat
}

ISBN 978-953-307-678-2

Hard cover, 338 pages

Publisher InTech

Published online 12, October, 2011

Published in print edition October, 2011

This book covers novel aspects of epilepsy without ignoring its foundation and therefore, apart from the classic issues that cannot be missing in any book about epilepsy, we introduced novel aspects related with epilepsy and neurocysticercosis as a leading cause of epilepsy in developing countries. We are looking forward with confidence and pride in the vital role that this book has to play for a new vision and mission. Therefore, we introduce novel aspects of epilepsy related to its impact on reproductive functions, oral health and epilepsy secondary to tuberous sclerosis, mithocondrial disorders and lisosomal storage disorders.

\title{
How to reference
}

In order to correctly reference this scholarly work, feel free to copy and paste the following:

Katarína Klobučnîková and Branislav Kollár (2011). Daytime Sleepiness and Changes of Sleep in Patients with Epilepsy, Novel Aspects on Epilepsy, Prof. Humberto Foyaca-Sibat (Ed.), ISBN: 978-953-307-678-2, InTech, Available from: http://www.intechopen.com/books/novel-aspects-on-epilepsy/daytime-sleepiness-and-changesof-sleep-in-patients-with-epilepsy

\section{INTECH}

open science | open minds

\section{InTech Europe}

University Campus STeP Ri

Slavka Krautzeka 83/A

51000 Rijeka, Croatia

Phone: +385 (51) 770447

Fax: +385 (51) 686166

www.intechopen.com

\section{InTech China}

Unit 405, Office Block, Hotel Equatorial Shanghai

No.65, Yan An Road (West), Shanghai, 200040, China

中国上海市延安西路65号上海国际贵都大饭店办公楼 405 单元

Phone: +86-21-62489820

Fax: +86-21-62489821 
(C) 2011 The Author(s). Licensee IntechOpen. This is an open access article distributed under the terms of the Creative Commons Attribution 3.0 License, which permits unrestricted use, distribution, and reproduction in any medium, provided the original work is properly cited. 